\title{
A New Manufacturing Improvement Model Based on Overall Equipment Effectiveness and Lean Maintenance
}

\author{
Anwar Meddaoui ${ }^{1}$, Ahmed En-nhaili ${ }^{2}$ \\ ${ }^{1}$ Department of Industrial Engineering École Nationale Supérieure d'Arts et Métiers, University of Hassan II, Casablanca, Morocco \\ ${ }^{2}$ Department of Mechanical Engineering École Mohammadia d'Ingénieurs, University of Mohammed V, Rabat, Morocco
}

Email address:

ameddaoui@gmail.com (A. Meddaoui), ennhaili.ahmed@gmail.com (A. En-nhaili)

\section{To cite this article:}

Anwar Meddaoui, Ahmed En-nhaili. A New Manufacturing Improvement Model Based on Overall Equipment Effectiveness and Lean Maintenance. International Journal of Engineering Management. Vol. 2, No. 2, 2018, pp. 15-28. doi: 10.11648/j.ijem.20180202.11

Received: April 16, 2018; Accepted: May 3, 2018; Published: May 29, 2018

\begin{abstract}
This paper proposes a new model for manufacturing effectiveness measurement and improvement basing on the TPM principles and lean maintenance improvement actions. Its methodology is founded on four main pillars. The first one deals with the maintenance process mapping. This part recaps previous published research on maintenance process optimization. The second pillar, the main Total Productive Maintenance (TPM) indicator Overall Equipment Effectiveness (OEE) is developed to include other parameters. The third part presents the core of this methodology. In this phase, principal wastes are considered and related to both lean tools and improvement actions. The last pillar concerns an industrial application of the proposed model. The paper presents two major contributions: designing a practical tool to understand the impact of improvement actions on industrial system's effectiveness and proposing a set of unavoidable actions and methods which adhere to their relative impact on the OEE rate. The proposed approach suggests to small organizations a new way to implement Lean methodology faster than usual by using directly appropriate tools to identify and kill waste sources. Further research could improve the proposed tool and thus reach a proposed study with other industrial application.
\end{abstract}

Keywords: Lean Maintenance, Overall Equipment Effectiveness, Process Approach, Maintenance Cost

\section{Introduction}

The world had recently experienced an economic crisis affected several levels in companies such as benefits deterioration and lack of competitiveness. Unfortunately, the survival of businesses depends on competitiveness and it shouldn't in any case stop from increasing. To keep up with this situation, manufacturers have to adopt some waste cutting strategies, the most well known in the industrial field is the Lean Manufacturing.

Lean theory originated in Toyota Production System created in the 1950's. Its basic ideology is to eliminate waste and reduce cost. Lean system implementation faces most of the time different limitations: the fastest complete Lean systems implementation takes two to three years, top management understanding is superficial [9], and lack of implementation know-how [21, 20], which is not advantageous for companies that want to face and survive unexpected situations in which immediate change and cost savings are requested.
One of the least exploited areas in the company is maintenance activities. Maintenance was usually seen as a strategy requiring high investments but delivering poorer rates of return $([1,19])$. The role of maintenance in modern manufacturing is becoming even more important, with companies adopting maintenance as a profit-generating business factor.

Most of the studies performed to assess the lean maintenance implementation are focused on performance release based on time studies [16, 6], but all of them are usually relative values and are not so significant regarding the quantification of cost savings. In his studies [4] employed the system dynamics approach to model and analyze a maintenance system with aiming at reliability evaluation and control.

OEE is a measure of equipment performance efficiency and is linked directly to $5 \mathrm{~S}$ and TPM. It's a measure which focuses mostly on production losses in which maintenance policy is one effect among many. By applying the principles of OEE, reduced values of downtime caused by breakdowns may help indicate the effectiveness of maintenance upon 
machine performance rates [6]. Studies of Singh and Singh (2014) highlights the contributions of continuous improvement function to ensure enhanced equipment improvement related issues, thereby affecting improvements in the manufacturing system performance. Results (case study indicated the average improvement in overall equipment effectiveness (OEE) of about $4.15 \%$, reduction of $88.22 \%$ in rejections, decrease in down time of 7.125 hours/week and the net cost savings of $\$ 2,420$.

This article will be focused on lean approach by applying smart actions to optimize maintenance activities, and effectiveness assessment by proposing improved Overall Equipment Effectiveness (OEE) using technical and economic factors.

Research methodology.

Methodology followed in this article is structured into four main phases as shown in figure 1 .

Description of the methodology phases showed in Figure 1 is developed as follows:

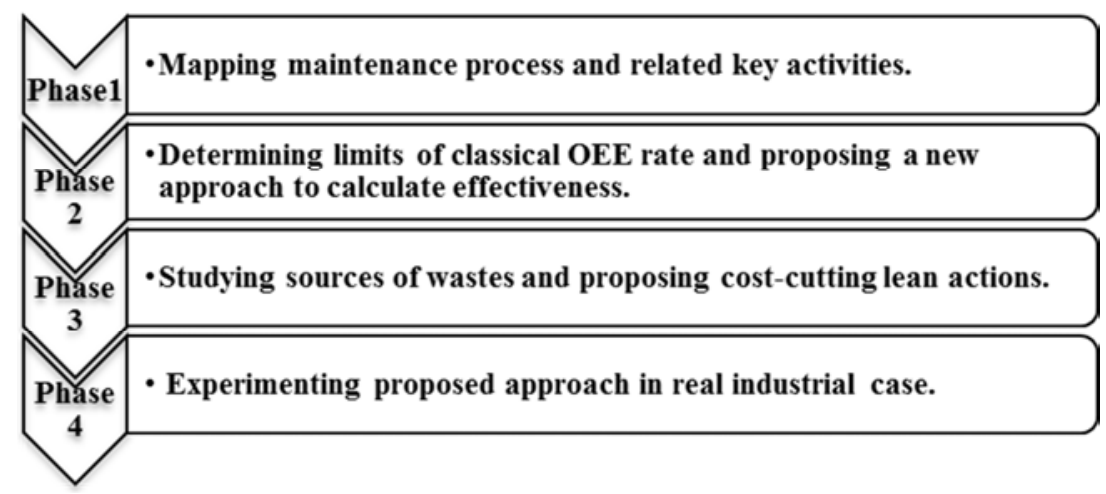

Figure 1. Methodology phases.

Phase 1: Mapping maintenance process and related key activities.

This step concerns maintenance process mapping into key activities based on a business process approach and works on maintenance process cost modelling through Business Process Reengineering (BPR) and Time Driven Activity Based Costing (TDABC) developed by [13]. In this phase key activities of maintenance are represented.

Phase 2: Determining limits of classical OEE rate and proposing a new approach to calculate effectiveness.

This phase starts with studying limits of classical Overall Equipment Effectiveness (OEE) and proposes a new approach to obtain effectiveness rate considering a global technical-economic context. The OEE calculation is developed taking in consideration economic factors.

Phase 3: Studying sources of wastes and proposing costcutting lean actions

The main objective in this phase is firstly to study leading and potential industrial wastes and link them to lean tools and secondly propose lean improvement actions which will be associated to the proposed effectiveness approach based on the new OEE rate. The impact of implemented actions on the OEE are quantified in the case study.

Phase 4: Experimenting proposed approach in real industrial case

The phase 4 is consecrated to the development of a real case study to test in an industrial process, the applicability and output results and to quantify experimented improvement actions impact on effectiveness rate.

\section{Literature Review}

While carrying out the current work, the literature was reviewed in three domains, namely Concept of process, lean manufacturing, concept of Overall Equipment Effectiveness, and concept of Time Driven Activity Based Costing. The information gathered by carrying out this literature review is described in the following three sections.

Concept of process:

Referring to the ISO 9000, the concept of process is any activity or set of activities that use resources to convert input elements into outputs, figure 2 .

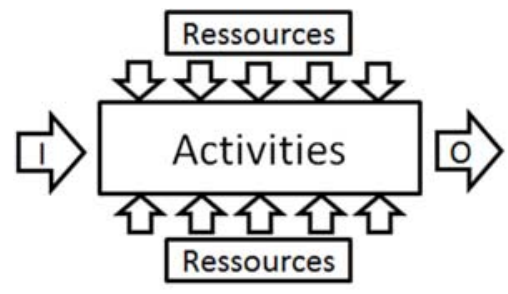

Figure 2. Concept of Process (ISO 9000).

Referring to the ISO 9001, a process can be divided into three pillars, operational process, supporting process and management process:

1. Operational process: It manages the production of a product or service, from search from customer needs to their satisfaction. It includes the activities dedicated to the life cycle of a product or service.

2. Supporting process: This process allows the operation of the other process by providing the necessary resources.

3. Management process: It contributes to the development of the company policy.

Elaoufir and Bouami. (2005) [8] had split the previous three main processes of maintenance into 5 intermediate 
processes then into 14 sub processes, and finally to 49 activities.

Concept of Lean:

According to Womack et al. (1990) [23], the basic Lean concept is to do more with less (e.g., less human effort, less equipment, less time and less space), while coming closer to customer requirements. Essentially, the term 'Lean' implies a series of activities or solutions to eliminate waste, reducing non-value added (NVA) operations, and improve the value added (VA) process [23]. The seven wastes frequently addressed in the lean manufacturing field are overproduction, over-processing, waiting, unnecessary transportation, inventory, motion and defects [11, 12].

This philosophy was initially introduced in Toyota Motor Company by Imai in 1986, to improve quality, productivity, and competitiveness of its product due to increasing competition in the world. With the implementation of Kaizen, the manufacturing sector of Japan has earned a lot and become a world class. Since then Kaizen has become a part and parcel of Japanese's manufacturing system [18], [22].

Concept of OEE:

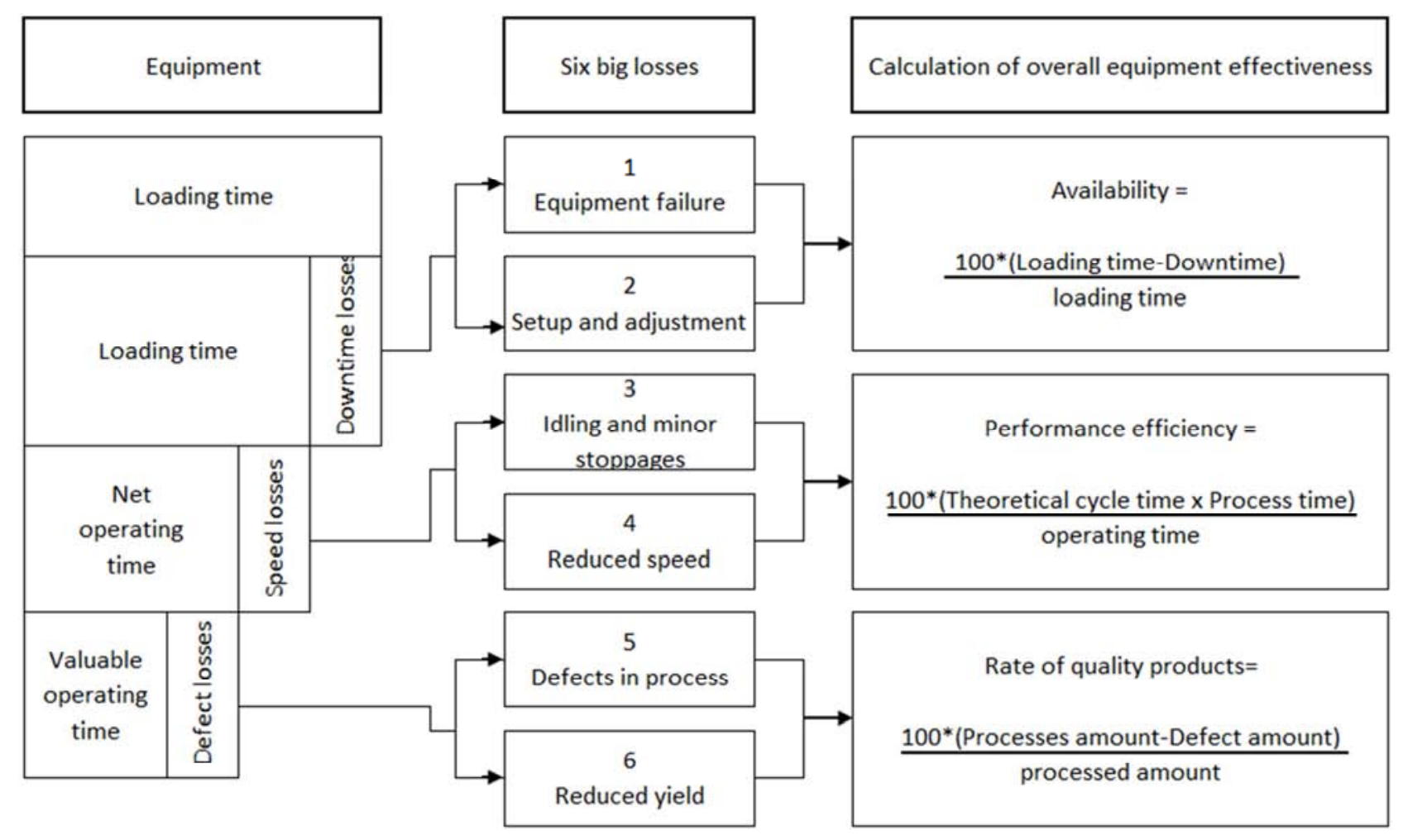

Overall equipment effectiveness $=$ Availability $\times$ Performance efficiency $\times$ Rate of quality
Overall Equipment Effectiveness (OEE) is a quantitative metric used primarily to identify and measure the productivity of individual equipment. It improves equipment performance by identifying and measuring the loss of potential sources namely availability, performance rate, and quality rate. OEE can be used to measure and compare the overall performance of an organization, compare the production line performance, and spot the machines that require immediate maintenance $[10,2]$.

Figure 3 highlights how OEE rate is related to equipment effectiveness, the six losses, and how it is calculated. For a typical lean production environment, an ideal OEE for a profitable TPM should be at least 85\% [16].

Overall Equipment Effectiveness (OEE) methodology is a proven approach to increase overall performance of equipment. Badiger, A. S. and Gandhinathan, R. (2008) [13] proposed a method to evaluate OEE by including a factor known as usability, in the OEE calculation method. Further, an approach is developed to evaluate the earning capacity of addressing the six big losses, with incremental improvement in OEE, as an extension to the maturity of OEE.

Figure 3. Overall equipment effectiveness (Nakajima, 1988).

Concept of TDABC:

Kaplan and Anderson. (2006) [10] presented developed activity-based costing to create the time driven activity-based costing. This method was presented as a revolutionary method in the field of determined costs. Considering the assignment of sources to activities, the method uses time equations. The principle of this method is based on the transformation of cost drivers to a time equation that expresses the time needed for the performing of the activity as the function of some drivers.

According to the specific study of Meddaoui and Bouami. on TDABC and decision making in the maintenance process, 
this approach is very important to maintenance cost understanding. It can be very useful to model both maintenance process costs and resources. Those authors experimented on the TDABC in a maintenance case study to demonstrate its capability in costs modelling and process capacity understanding.

\section{To a New Approach to Evaluate Effectiveness and Improvement}

As described before, the objective of the research methodology beyond defining maintenance key activities (phase 1) is studying classical OEE limits and proposing a new effective rate reflecting also the process cost evolution (phase 2) but especially integrating all potential improvement actions associated with leading lean maintenance tools in the

global scheme of cost cutting and improved effectiveness (phase 3). The last step in the current study is the experimentation of the proposed approach to facilitate lessons learned as feedback for conclusion and further studies.

Phase 1:

In this phase a global process mapping methodology is presented. In order to map business processes of the company, each department must be considered separately to simplify the Lean implementation, the steps followed to list main activities is described in figure 4.

After definition of studied department key activities, time and cost of each activity are defined using the Time Driven Activity Based Costing method. For this need, findings of Meddaoui and Bouami are used as support.

It represents the company name of which we want to represent the process.

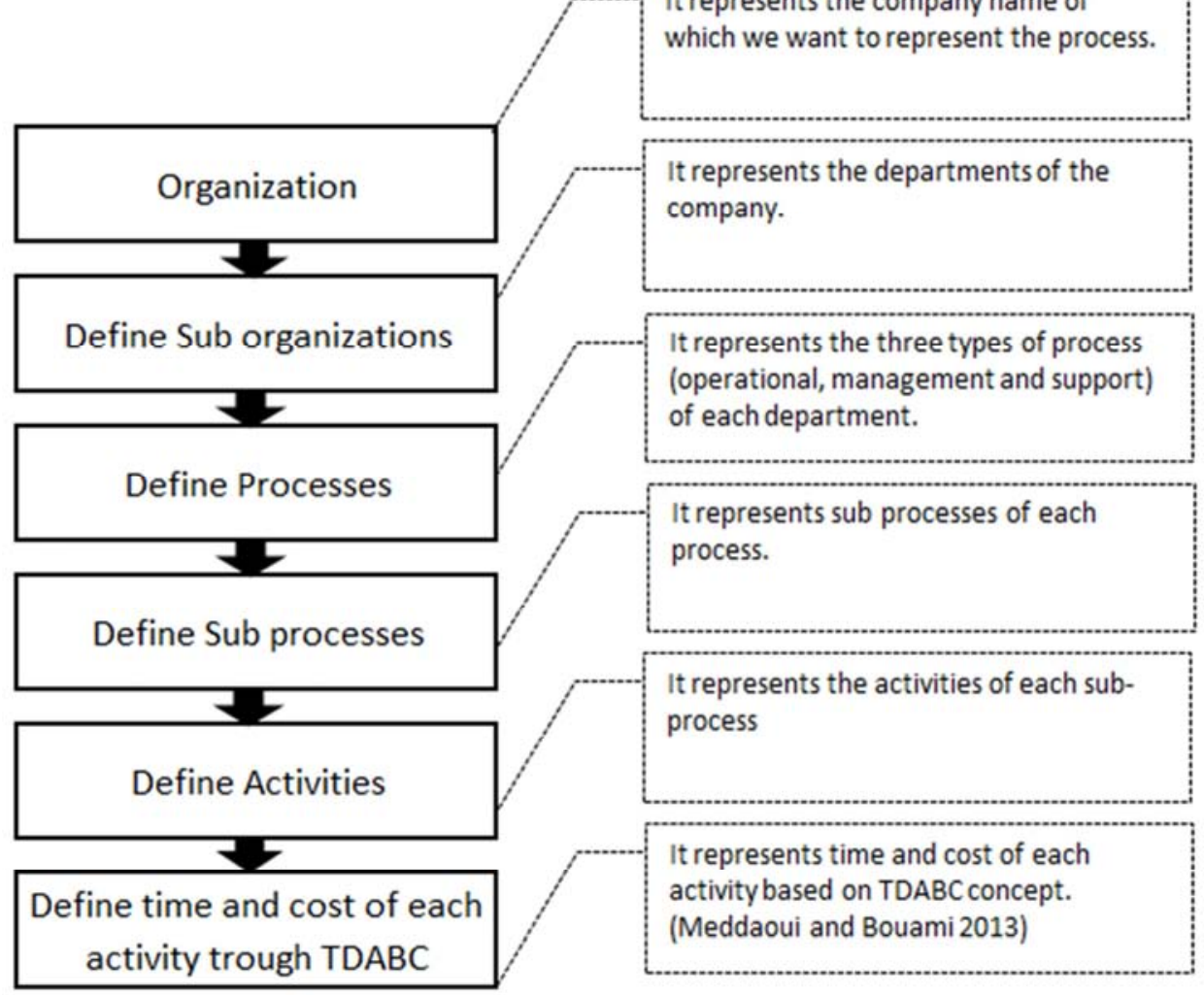

Figure 4. Process mapping steps.

Phase 2:

The overall equipment effectiveness (OEE) is a hierarchy of metrics to evaluate how effectively a manufacturing operation is utilized. OEE is calculated as the product of its three contributing factors: Availability, Performance, and Quality:

$\mathrm{OEE}=$ Availability $\mathrm{x}$ Performance $\mathrm{x}$ Quality

Availability $=$ Operating Time/ Planned Production Time

Performance $=$ Ideal Cycle Time/ (Operating Time/ Total Pieces)

Quality $=$ Good Pieces/ Total Pieces

OEE has been the most broadly adopted measurement.
However, the output of OEE is usually a relative value and it cannot allow users to quickly estimate a production line's potential savings costs as a result of OEE improvements and can't help guide the improvement efforts actions for companies engaging in a continuous improvement initiatives.

A new paradigm has been emerged that tries to link OEE to costs (Atkinson, 2007), other contributions try to evaluate how effectively a manufacturing operation is utilized by mainly using both maintenance and finance efficiency (Ennhaili et al. 2014) [7].

According to [2]., TDABC and OEE provide an interesting pair of tools that managers can use to classify and cost-idle 
time and the downtime, speed, and quality losses associated with the fixed factors of production. Such information should be useful in identifying and prioritizing opportunities for operations improvement".

According to [7] maintenance VSM is used to describe main operational processes of maintenance: preventive and corrective. The discussed application gives an idea on maintenance global efficiency indicator using Non-Value added time, Value added time, Maintenance Efficiency and Maintenance Financial Efficiency.

A new reasoning purpose can be developed to have a better understanding where opportunities for improvement exist when a continuous improvement initiative has OEE as its key performance indicator and can answer also to the questions how do you demonstrate to management the value of a one-point improvement in OEE? How can use OEE number to calculate savings through the three contributing factors: Availability, Performance, and Quality?

The purpose will overcome classical OEE limits and will be a development of Atkinson's contribution research. (2007). Classical OEE can firstly be consolidated by a control rate: Average Cost Performance (ACP) related to each cost elements (direct and indirect) to study the cost efficiency based on budgeted and actual cost driver rate (CDR). The main objective pertaining to the use of ACP is to integrate fourth contribution factors in order to assimilate financial performance into the OEE calculation and provide a technical-economic OEE: (OEE-TE). Secondly, calculation results can be used to demonstrate to management the value of a one-point improvement in OEE by calculating savings by each OEE Category.

ACP is defined as the ability of an operational function to respect budgeted cost elements. The method is based on budgeted and actual CDR calculated by using the basics of TDABC.

CDR is defined as cost (Direct and Indirect cost) per hour consumed by the cost element. The primary objective of the $\mathrm{CDR}$ is to calculate savings in value related to improvement hours of each OEE factor.

ACP development can be summarized by the following steps mentioned below:

1 Identify Cost elements: Universal Cost category: Labor, Overheads, and Depreciation

2 Link Cost elements to each OEE Function: Affectation of each cost elements to the OEE contribution Factor.

3 Identify Budgeted costs: Budgeted costs defined in year $\mathrm{N}-1$ as objective for year $\mathrm{N}$

4 Identify cost driver rate: The cost per each hour consumed by the cost element by using the basics of the TDABC

5 Calculate cost performance: Cost performance for each cost element: CDR Budget/ CDR Actual

6 Calculate Average Cost Performance: Average (CDR 1; 2 ......n)

OEE-TE $=$ Availability $x$ Performance $x$ Quality*ACP

$\operatorname{ACP}\left(\mathrm{F}_{\mathrm{i}}\right)=\sum \mathrm{CDR}_{\mathrm{i}}$ Budget $/ \sum \mathrm{CDR}_{\mathrm{i}}$ Actual

ACP: Average Cost Performance (for each OEE function $\mathrm{F}_{\mathrm{i}}$ )

$\mathrm{F}_{\mathrm{i}}$ : OEE factors (Availability $\mathrm{i}=1$, Performance $\mathrm{i}=2$,
Quality i=3)

$\mathrm{CDR}_{\mathrm{j}}$ : Cost Driver Rate (for each cost elements $\mathrm{j}$ )

Finally, absolute saving value on OEE is calculated by an evaluation of each saving OEE factor hours with the total cost driver rate (Saving hours ${ }_{(\mathrm{Fi})} * \mathrm{CDR}_{(\mathrm{Fi})}$ ) in order to have an overview of cost reduction and evaluate the efficiency of the corrective actions made to improve OEE between two periods. The sum of cost reduction on each function will give the global absolute value on OEE improvement.

Phase 3:

According to (Ohno, 1985; Bicheno, 2000; and Davies, 2003) the wastes frequently addressed in lean manufacturing are:

1. W1- Overproduction: example of too much preventive maintenance

2. W2- Waste of waiting: example of waiting for resources

3. W3- Waste of transporting: example of transport of equipment

4. W4- Waste of processing: example of non-standard preventive maintenance

5. W5- Waste of inventory: example of excessive stock

6. W6- Waste of motion: example of double handling

7. W7- Waste of defect: example of poor maintenance

8. W8- Waste of human potential: example of lack of training

9. W9- Waste of inappropriate systems: example of poor information

10.W10- Waste of energy and water: example of energy management

11.W11- Waste of material: example of too much preventive maintenance

12.W12- Waste of service and office: example of poor and service operation

13.W13- Waste of customer time: example of poor procedure

14.W14- Waste of defecting customers: example of poor maintenance

Several lean tools were created; most used tools are listed below (Womack and Jones, 1996; Womack et al. 1990; Davies. 2003) gave us a summary and a definition of each tool.

1. Value stream mapping: is a tool to map material and information flow of a productive process.

2. 5 Why: Its method to trace a cause by asking 'why' five times when confronted with a problem

3. 5S house keeping: It's a system for cleaning, organizing and maintaining a work area.

4. Pareto: It's a tool to represent data on graphs in order of frequency of occurrence.

5. A3 Report: It's a presentation of a problem on a single sheet of paper, including all the background information on the problem, root causes, potential solutions and action plans.

6. Bottleneck Analysis: It's a process to identify the step in the process where the capacity available is less than the capacity required.

7. 5M: It displays graphically the factors and underlying 
causes of a defect or problem.

8. Check Sheet: It's a written document listing critical elements to be checked on a regular basis.

9. Kaizen Events: It's a philosophy and set of tools dedicated to small increments of continuous improvement at all levels of a company.

10.Kanban: Kanban is the tool for managing and achieving just in time philosophy.

11.One Piece Flow: One Piece Flow is a scheduling technique where the batch size is set to one.

12.Poke-a-Yoke/Error-proofing: It's a tool which prevents the occurrence of defects

13. Single Minute Exchange of Dies: is an approach to machine setup and design that strives to minimize setup times.

14.Spaghetti Diagram: It's a tool to monitor the actual flow of material or workers in a process.

15.Standardized Work: It's a technique where process procedures are documented so that an ideal standard work process is developed.

16.Visual Management: It's a technique which provides visual cues that alert anyone in an area on how a process should be completed, or how a workstation should be setup.

17. Skill matrix: It's a chart used to identify current capability and future training needs to developp the skills of employees

To identify the area for lean tools application, first the adequate lean tool was highlighted for each kind of waste Table 1 (' $i$ ' for improvement and ' $d$ ' for detection), in Table 2 the wastes were linked to activities.

Table 1. Link between wastes and lean tools.

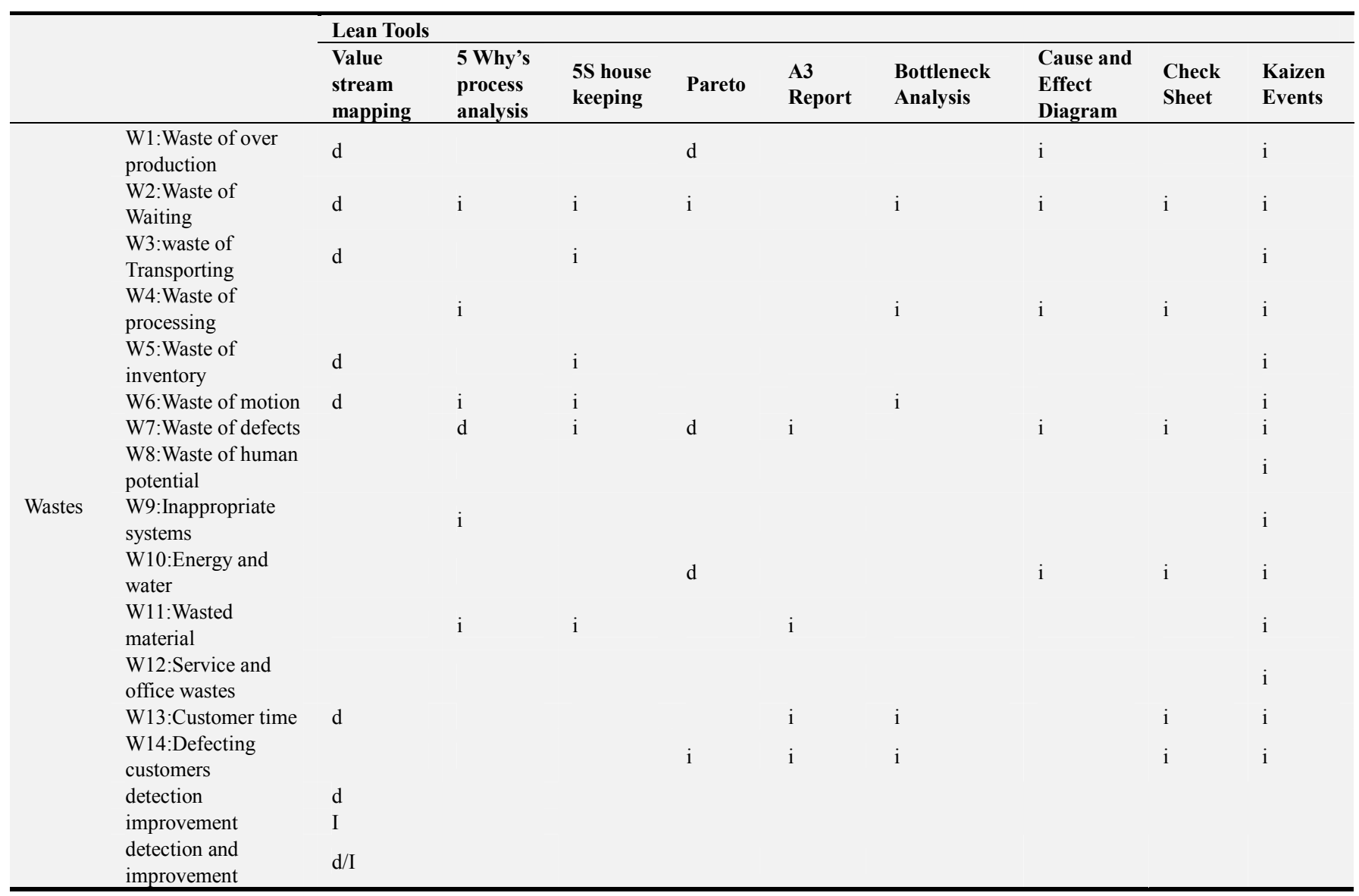

Table 1. Continued.

\begin{tabular}{|c|c|c|c|c|c|c|c|c|c|}
\hline & & \multicolumn{8}{|c|}{ Lean Tools } \\
\hline & & Kanban & $\begin{array}{l}\text { One } \\
\text { Piece } \\
\text { Flow }\end{array}$ & $\begin{array}{l}\text { Poke-a- } \\
\text { Yoke/Error- } \\
\text { proofing }\end{array}$ & $\begin{array}{l}\text { Single Minute } \\
\text { Exchange of } \\
\text { Dies (SMED) } \\
\end{array}$ & $\begin{array}{l}\text { Spaghetti } \\
\text { Diagram }\end{array}$ & $\begin{array}{l}\text { Standardized } \\
\text { Work }\end{array}$ & $\begin{array}{l}\text { Visual } \\
\text { Management }\end{array}$ & $\begin{array}{l}\text { Skill } \\
\text { matrix }\end{array}$ \\
\hline \multirow[t]{3}{*}{ Wastes } & $\begin{array}{l}\text { W1:Waste of over } \\
\text { production } \\
\text { W2:Waste of } \\
\text { Waiting }\end{array}$ & $\mathrm{i}$ & & & $\mathrm{i}$ & $\mathrm{d} / \mathrm{i}$ & $\mathrm{i}$ & $\mathrm{i}$ & \\
\hline & $\begin{array}{l}\text { W3:waste of } \\
\text { Transporting }\end{array}$ & $\mathrm{i}$ & & & $\mathrm{i}$ & $\mathrm{d} / \mathrm{i}$ & & & \\
\hline & W4:Waste of & & $\mathrm{i}$ & & & & $\mathrm{i}$ & & \\
\hline
\end{tabular}




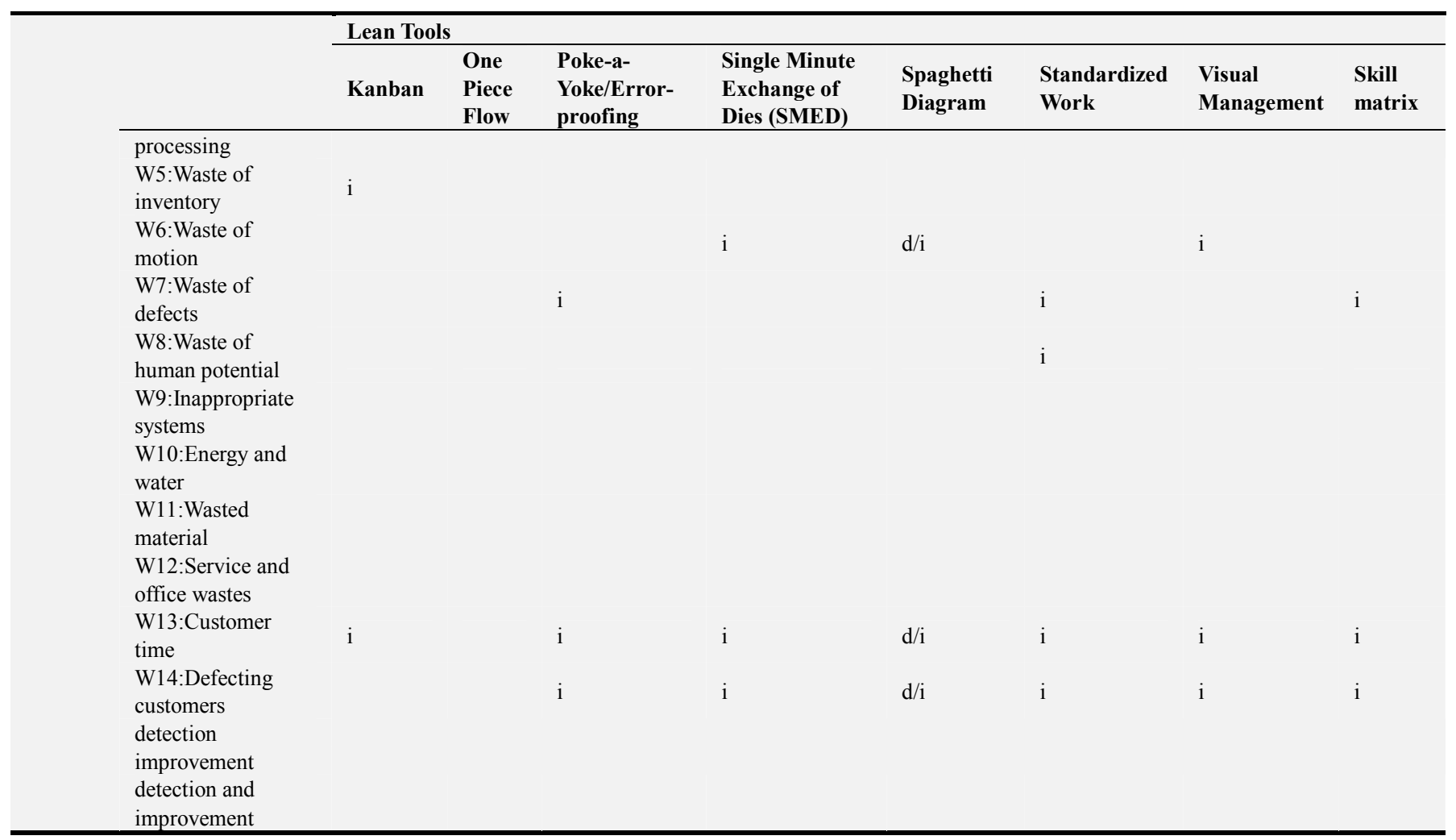

Table 2. Link between maintenance activities and wastes

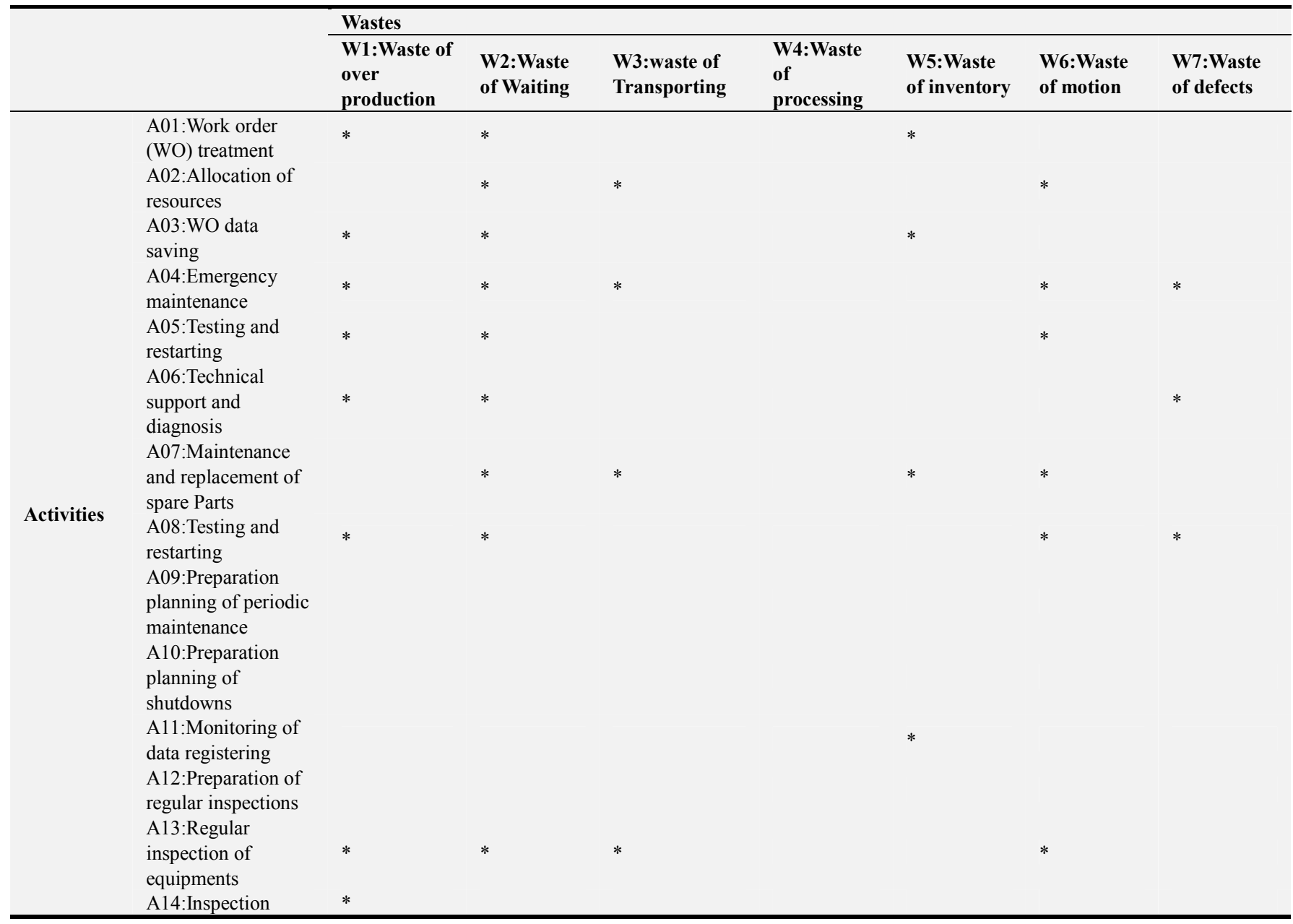




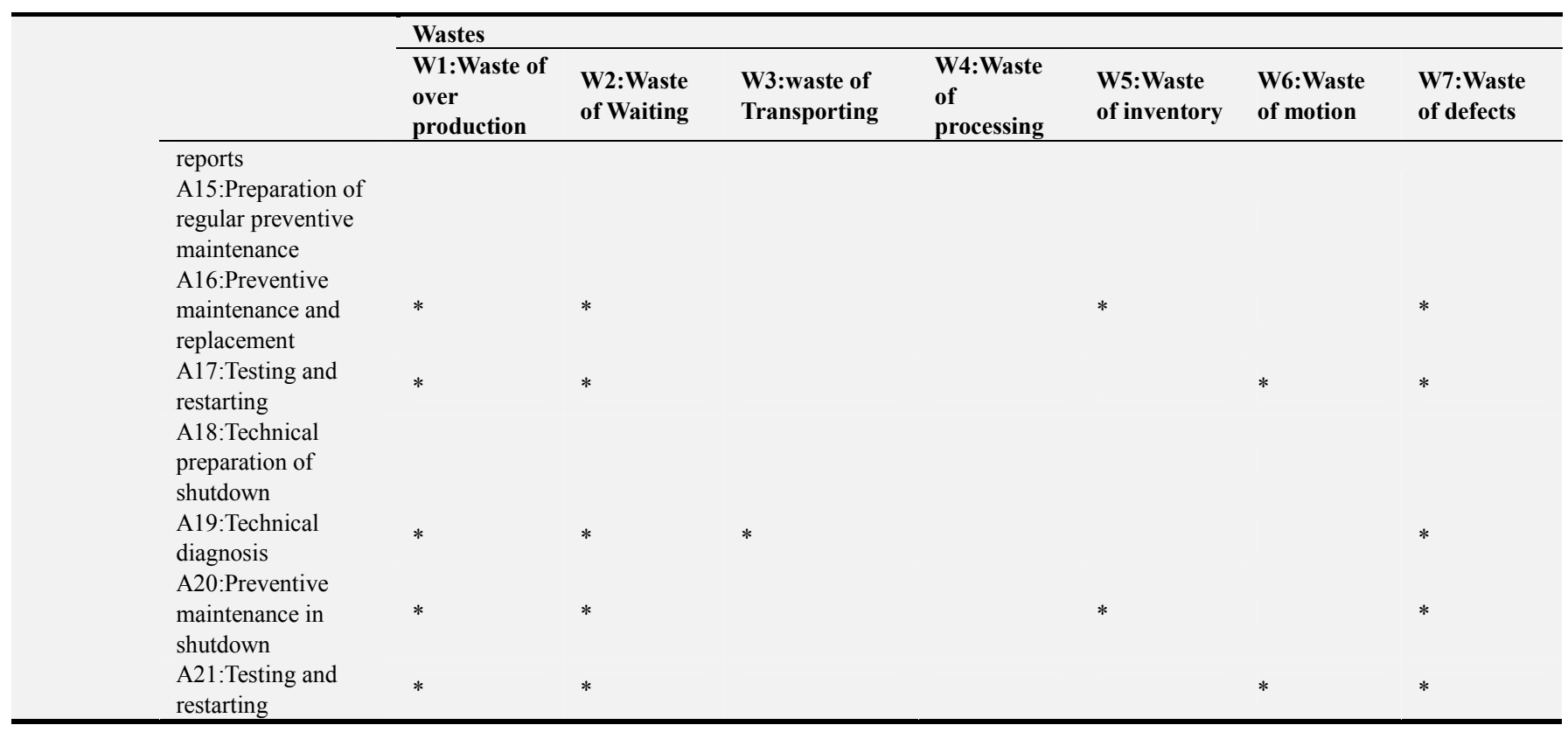

Table 2. Continued.

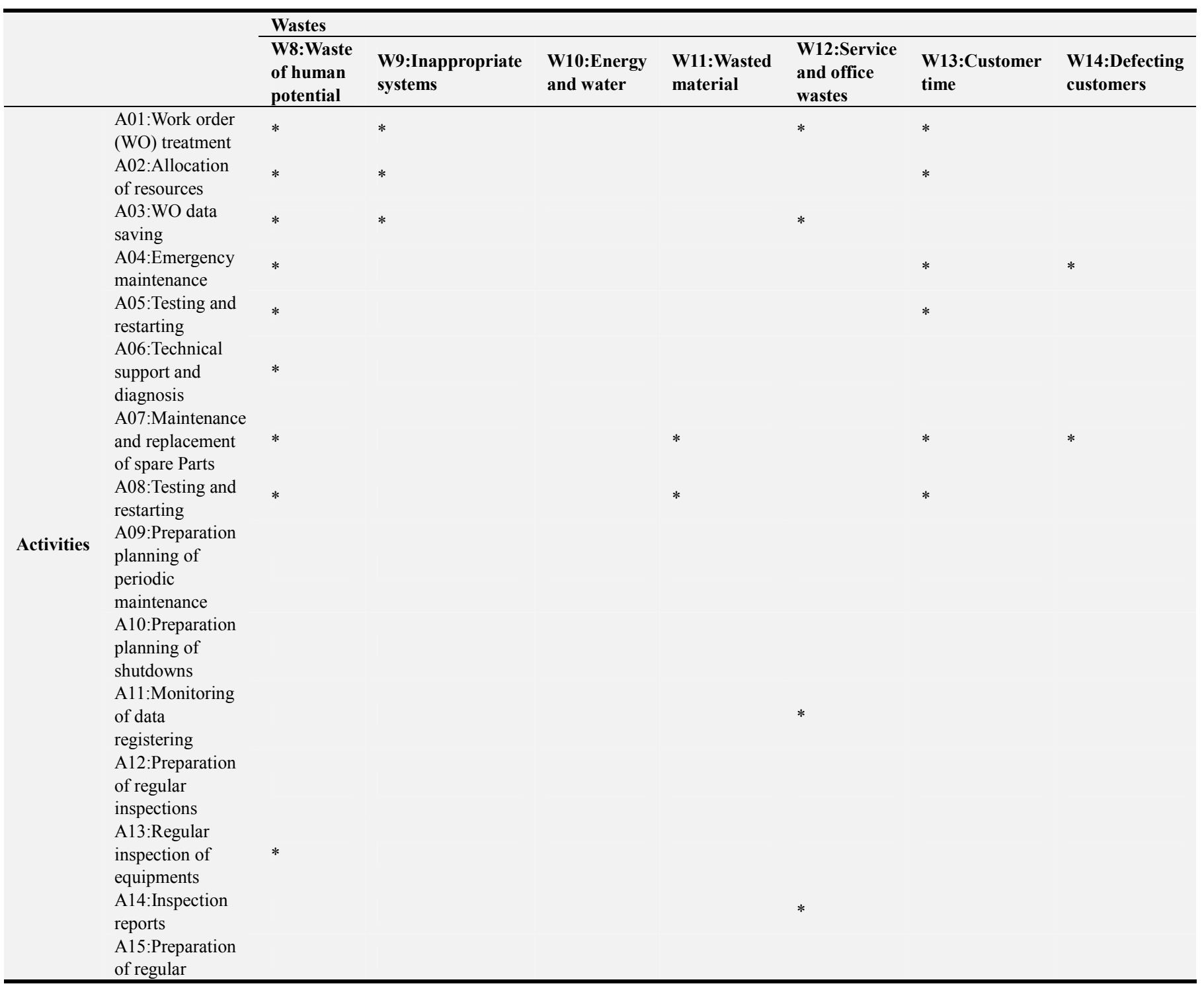




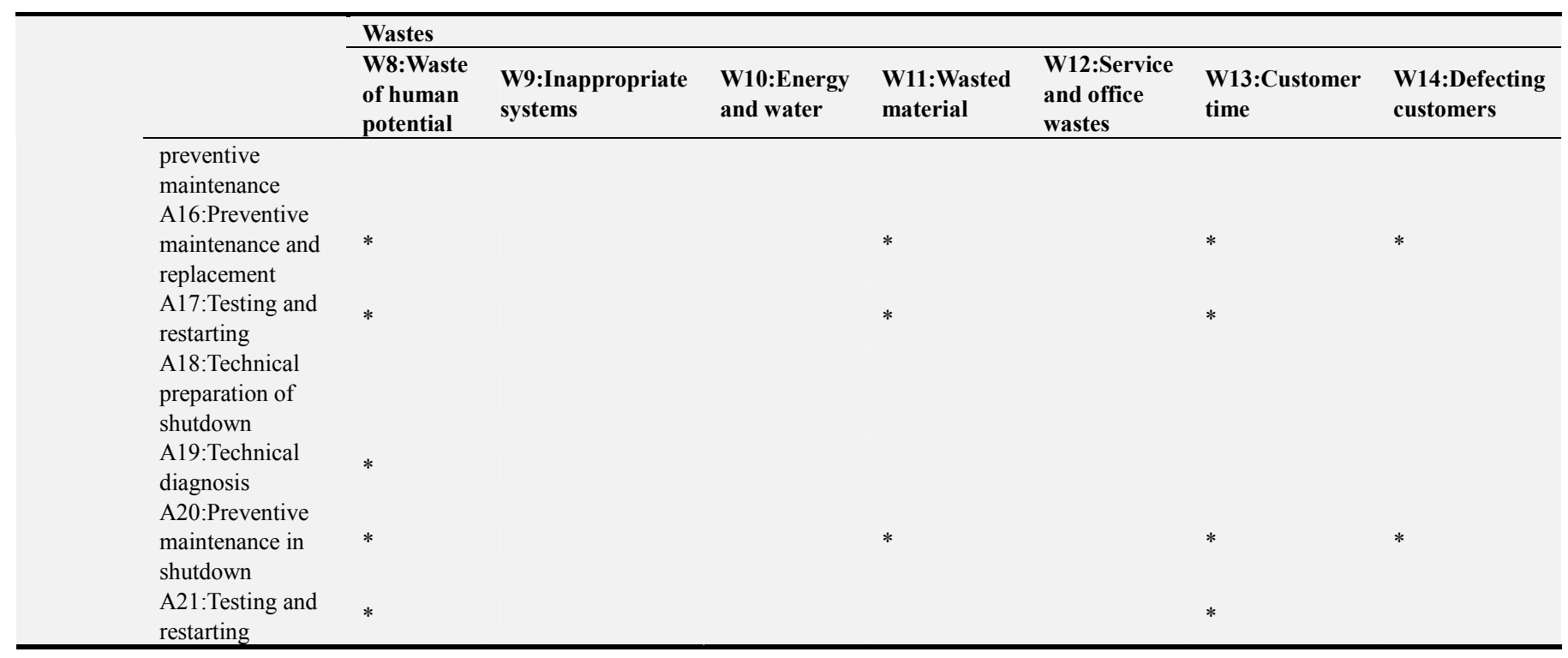

Table 3. Proposed actions with their weights.

\begin{tabular}{|c|c|c|}
\hline ID & Actions & Weight \\
\hline IA 01 & Definition of work order procedure treatment & 0.01 \\
\hline IA 02 & Implementation of electronic work order emission system & 0.03 \\
\hline IA 03 & Optimization of physical and information flow & 0.01 \\
\hline IA 04 & Detection and reduction of waiting events & 0.01 \\
\hline IA 05 & Work only on one problem at the same time & 0.01 \\
\hline IA 06 & Definition of standard work procedures & 0.01 \\
\hline IA 07 & Definition of clear reaction plan based on the work order & 0.01 \\
\hline IA 08 & Identification of the constraint processes & 0.01 \\
\hline IA 09 & Insure safety and maintainability of machines & 0.04 \\
\hline IA 10 & Insure safe access to ensure maintenance inspection and diagnosis & 0.04 \\
\hline IA 11 & Control of emergency maintenance procedure & 0.03 \\
\hline IA 12 & Organization of maintenance tools & 0.03 \\
\hline IA 13 & Organization of the shop floor for easy access to the equipment & 0.03 \\
\hline IA 14 & Availability of diagnosis material & 0.02 \\
\hline IA 15 & Reliability of diagnosis material & 0.03 \\
\hline IA 16 & Definition of diagnosis procedure & 0.02 \\
\hline IA 17 & Control of diagnosis procedure & 0.02 \\
\hline IA 18 & Availability of communication tools & 0.02 \\
\hline IA 19 & Organization of maintenance tools & 0.02 \\
\hline IA 20 & Management of spare parts stock & 0.04 \\
\hline IA 21 & Improvement of the visual management of the equipment & 0.02 \\
\hline IA 22 & Planning of preventive maintenance during holidays & 0.01 \\
\hline IA 23 & Definition of inspection frequency by equipment & 0.02 \\
\hline IA 24 & Definition of regular inspection check list & 0.02 \\
\hline IA 25 & Availability of adequate tools for disassembly/Replacement/Assembly & 0.02 \\
\hline IA 26 & Implementation of E- check list/report & 0.03 \\
\hline IA 27 & Implementation of tele-maintenance (supplier of the equipment) & 0.02 \\
\hline IA 28 & Automatic data saving, and generation of reports (Pareto charts) & 0.02 \\
\hline IA 29 & Identification $20 \%$ worst cases & 0.03 \\
\hline IA 30 & Reduction of technician movements & 0.03 \\
\hline IA 31 & Reduction of change over & 0.05 \\
\hline IA 32 & Cleanness of the equipment & 0.02 \\
\hline IA 33 & Definition of Disassembly/Replacement/Assembly procedure & 0.02 \\
\hline IA 34 & Standardization and simplification of access to machines & 0.02 \\
\hline
\end{tabular}




\begin{tabular}{lll}
\hline ID & Actions & Weight \\
\hline IA 35 & Control of Disassembly/Replacement/Assembly procedure & 0.02 \\
IA 36 & Identification of real root cause & 0.03 \\
IA 37 & Definition of causes related to 5M & 0.03 \\
IA 38 & Definition of clear check list for validation test & 0.03 \\
IA 39 & Quality control of purchased spare parts & 0.02 \\
IA 40 & Implementation of error proofing systems & 0.04 \\
IA 41 & Identification of relevant points to be checked & 0.03 \\
IA 42 & Description of problems with actions and background & 0.03 \\
\hline
\end{tabular}

Through these two Tables the possible lean tool which can be used to improve each activity could be pinpointed easily.

Basing on table 1 and table 2, the most adequate actions to improve maintenance activities are summarized in the table 3. The weight of each action was calculated based on the AHP methodology (Meddaoui and Bouami. 2014) [14].

Each action could have an impact on the OEE through positive impact either on quality, performance or availability. This impact was defined based on the nature of each action.

The implementation area of each action and its impact on specific part of the OEE is presented in Figure 5.

Figure 5 presents an inter-connection between activities (Corrective and preventive maintenance), improvement actions and OEE-TE contribution factors affected. Output is global improved OEE-TE issued from the integral inter- connections. Some inter-connections can affect more than one OEE-TE contribution factor (Example A04-IA 25: affects Availability \& Performance)

Phase 4:

As mentioned before, the proposed approach will be implemented in the maintenance department. Consideration is only placed on the operational process for its consistency referring to Meddaoui and Bouami. (2013) [13]., and other similar studies which demonstrate that the operational process is the most expensive. It has been established that corrective maintenance and preventive maintenance represent approximately $80 \%$ of the total maintenance cost. In fact, the current study will be limited to the two sub-processes of the operational process.

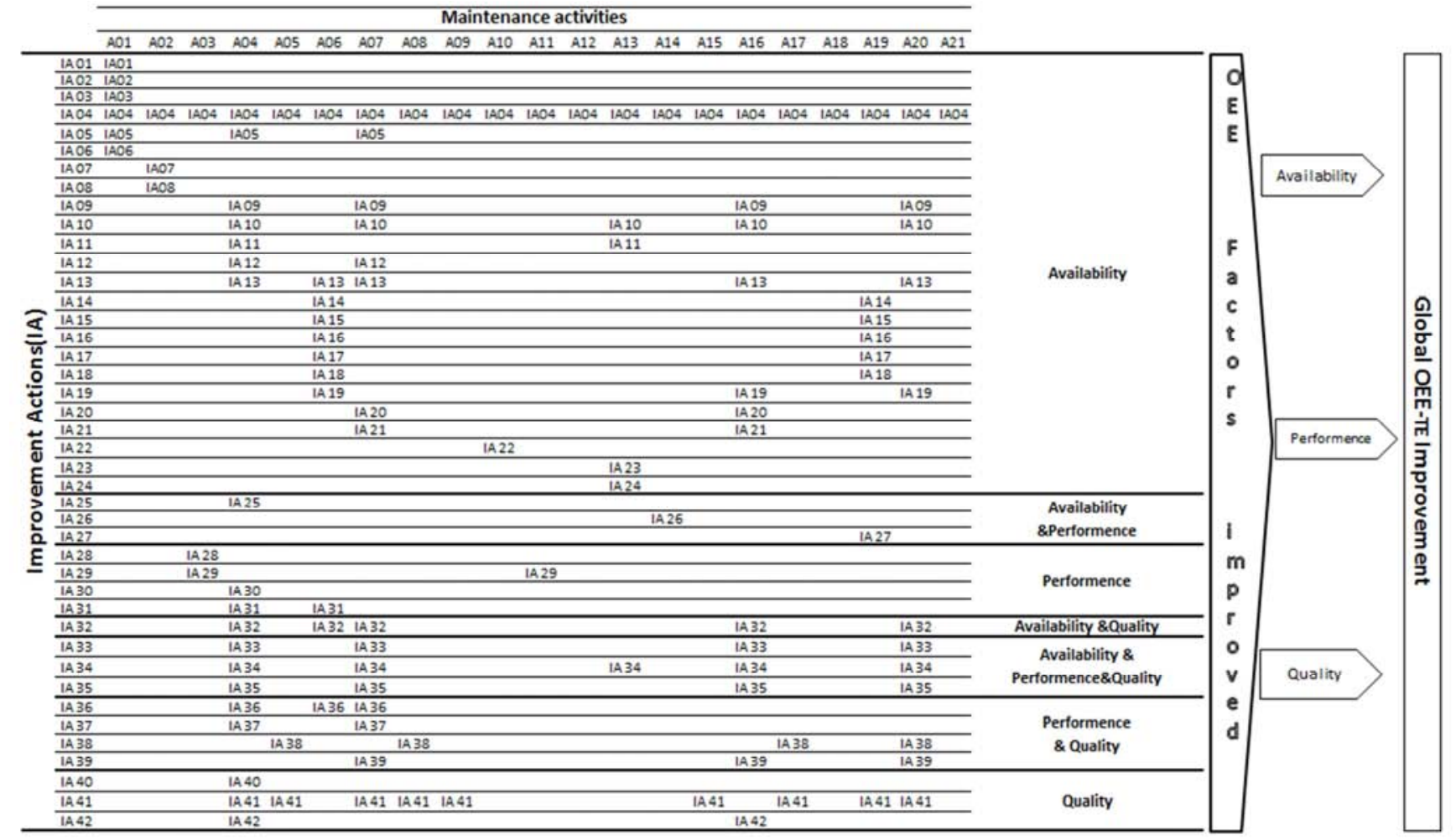

Figure 5. Implementation area of actions and impact on OEE.

\section{Case Study}

\subsection{Company Information}

The company chosen is an American automotive supplier specialized in the design and manufacture of interior trim parts (instrument panels, center consoles and door panels) and other disciplines, the company was recently established in Morocco, and it has 26000 employees around the world where an insistence of its distribution is done in four countries. Its main 
customers are BMW, Ford, GM and many others.

Maintenance department:

The maintenance department has as its missions: purchasing installation and maintenance of all plant equipment with maximum reliability and efficiency. Pillars of maintenance human resources are described as follows:

1 Maintenance manager

1 Method engineer

6 Maintenance technicians of which 2 Tool shop technician and 1 Spare-part agent.

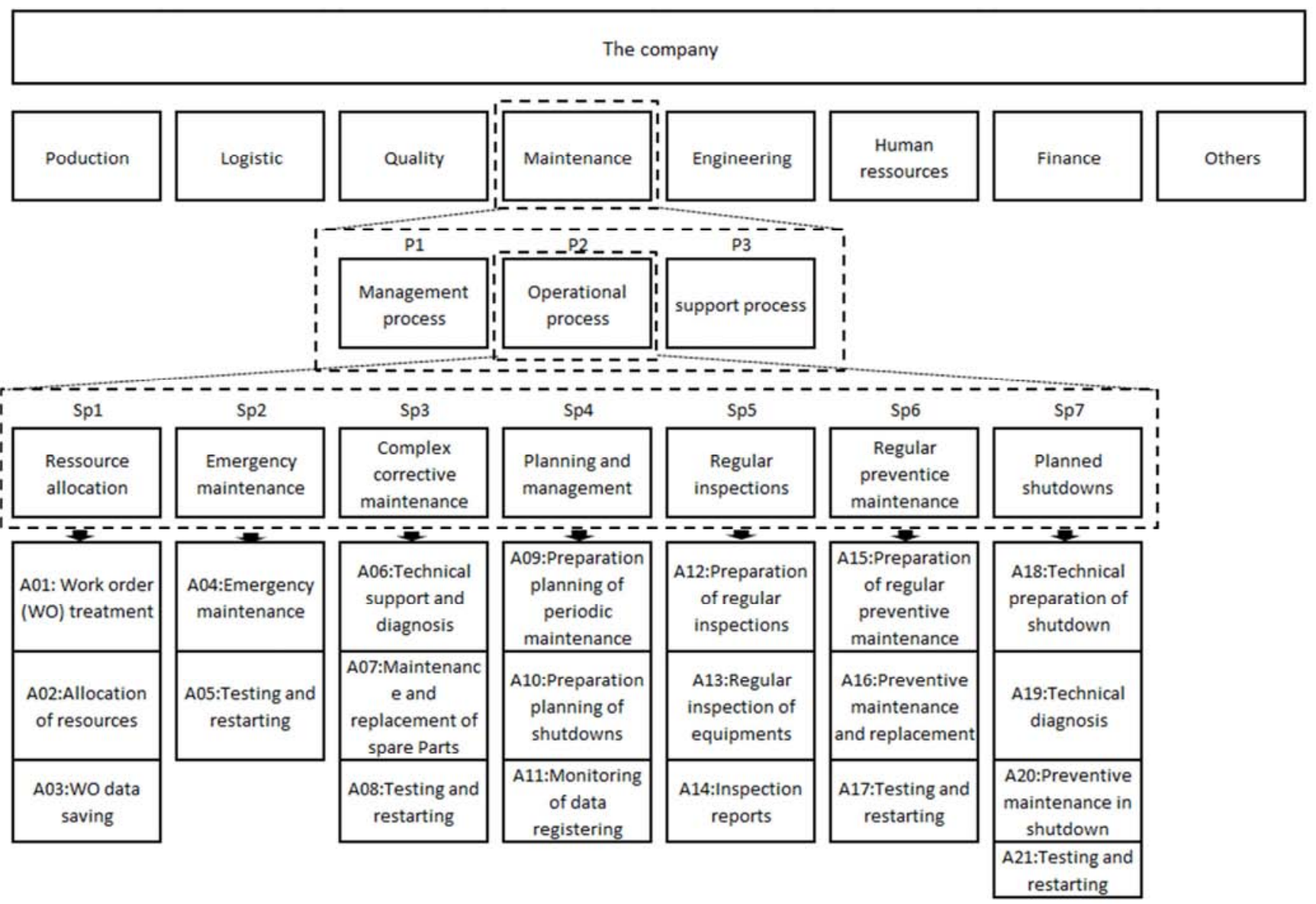

Figure 6. Maintenance process and key activities.

10 Trimmer machine and molding

Maintenance team is supported by 3 supervisors and production Manager

The main activity of the company is provided by 09 injection units which should be maintained by the presented maintenance department.

Mapping processes and key activities of maintenance department

As described before, the maintenance department is chosen to be mapped in order to experiment the proposed model in part 3. As presented in figure 6 , the focus is allocated to the operational process by describing the 9 sub-processes, as emergency maintenance and preventive maintenance in shutdowns, so as to correlate the 21 associated activities.

After definition of key activities, time and cost of each activity were determined based on TDABC approach (Meddaoui and Bouami 2013) [13], see table 4.
Table 4. Plant maintenance data (activity's time and cost) for Feb- 2014.

\begin{tabular}{llll}
\hline Process & Act. ID & Cost (MAD) & Time (Min) \\
\hline & A01 & 42941.79 & 6472 \\
& A02 & 39037.99 & 5860 \\
Corrective & A03 & 54876.26 & 8307 \\
maintenance & A04 & 61568.49 & 9917 \\
(CM) & A05 & 13942.14 & 2222 \\
& A06 & 8922.97 & 1352 \\
& A07 & 80306.72 & 12852 \\
& A08 & 10038.34 & 1481 \\
& A09 & 2230.39 & 332 \\
& A10 & 1022.26 & 164 \\
& A11 & 861.95 & 148 \\
Preventive & A12 & 5878.01 & 999 \\
maintenance & A13 & 16100.65 & 2572 \\
(PM) & A14 & 1765.73 & 265 \\
& A15 & 3345.59 & 533 \\
& A16 & 19515.93 & 2951 \\
& A17 & 1686.73 & 270 \\
& A18 & 360.12 & 59 \\
& A19 & 499.51 & 82 \\
& A20 & 115736.46 & 19414 \\
& A21 & 2090.99 & 309 \\
\hline
\end{tabular}




\subsection{Data Before Improvement}

OEE-TE is calculated for the nine presented injection units and consolidated for the entire plant. Availability and Performance factors are based on 'hours' except for the third factor Quality, which is based on bad and good produced parts. As described in part 3, in order to obtain final results of
OEE-TE, factors are weighted by injection unit's specific ACP. Technical and Economic efficiency is calculated for the month of February 2014 as a first step before the establishment of lean maintenance improvement, Table 5.

In order to give the calculating procedure of ACP, Table 6 below describes the link between cost elements $\mathrm{CE}$, the three factors (F1, F2 and F3) and budgeted/actual CDR.

Table 5. OEE-TE calculation before establishment of lean maintenance improvement.

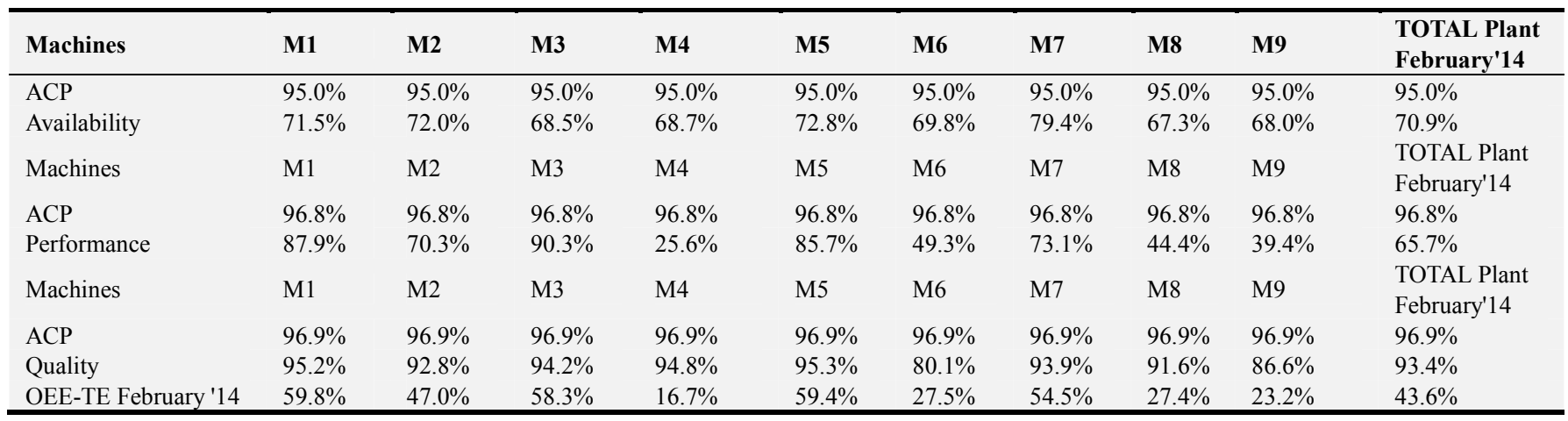

\subsection{Implementation and Results}

A versatile team is formed in cooperation with external stakeholders to constitute a piloting committee of lean maintenance improvement. Implementation is started at the end of February 2014 with involved stakeholders in maintenance and plant finance controlling department.

Improvement actions are preselected in a first step with the aim of killing time and delaying wastes recurrent problems in maintenance activities as well as its adaptation to the experimented case study.

Improvement actions implemented for each maintenance activity are detailed below, Figure 7 .
Numbers in Figure 7 represent improvement points for each interconnection binomial by using improvement action's weighted percentage allocated to saving time.

By using the Matrix, time and delay are reduced for each maintenance activities. By consequence contribution factors are respectively improved:

Availability: $+3.68 \mathrm{Pt}$,

Performance: $+7.46 \mathrm{Pt}$,

Quality: +1.1Pt.

Systematically global OEE-TE improvement is +8 , $3 \mathrm{Pt}$ by using adequate interconnection between activities and improvement actions.

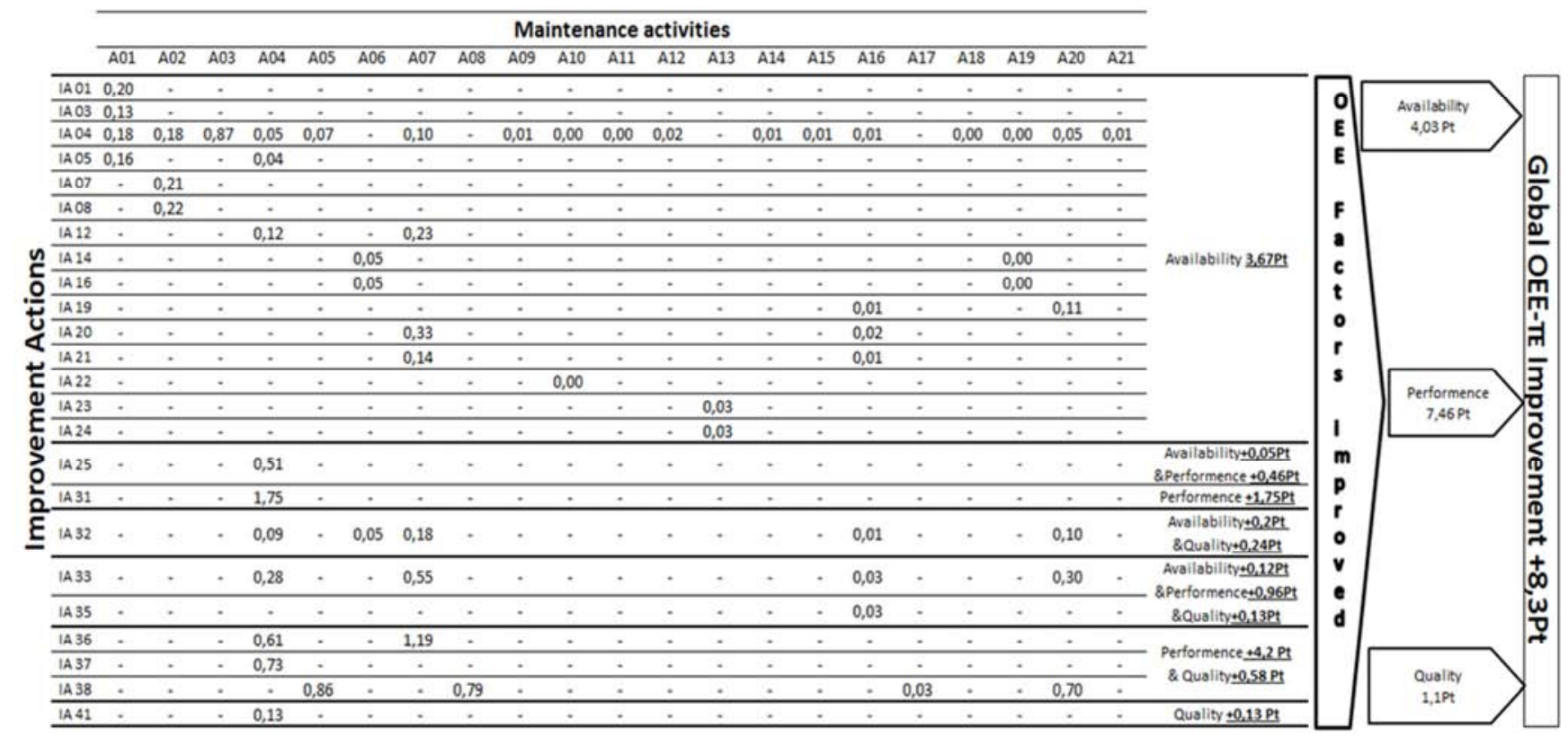

Figure 7. Global scheme of effectiveness improvement. 
Table 6. ACP Calculating procedure

\begin{tabular}{|c|c|c|c|c|c|c|c|}
\hline CPG Cost pool generator & $\begin{array}{l}\text { CDR Budget } \\
\text { Bugeted unit } \\
\text { Cost driver } \\
\text { rate }\end{array}$ & $\begin{array}{l}\text { F1 } \\
\text { Availability }\end{array}$ & $\begin{array}{l}\text { F2 } \\
\text { Performance }\end{array}$ & $\begin{array}{l}\text { F3 } \\
\text { Quality }\end{array}$ & $\begin{array}{l}\text { CDR Actual } \\
\text { Actual Unit } \\
\text { Cost driver } \\
\text { rate }\end{array}$ & $\begin{array}{l}\text { CPP Cost } \\
\text { Performence }\end{array}$ & $\begin{array}{l}\text { ACP } \\
\text { Average } \\
\text { Cost } \\
\text { performence }\end{array}$ \\
\hline Labor cost : Trimmer & 29 & $*$ & & & 31 & $93 \%$ & \\
\hline Labor cost : Maintenance Manager & 13 & $*$ & & & 13 & $100 \%$ & \\
\hline Labor cost : Production Manager & 16 & $*$ & & & 16 & $100 \%$ & \\
\hline Labor cost : Supervisor & 20 & $*$ & & & 20 & $100 \%$ & \\
\hline Labor cost : Mainatenance Technician & 23 & $*$ & & & 24 & $93 \%$ & \\
\hline Ovehads costs : Maintenance cost & 90 & $*$ & & & 95 & $95 \%$ & $96 \%$ \\
\hline Direct Labor costs & 37 & & $*$ & & 38 & $97 \%$ & $97 \%$ \\
\hline Other indirect labor costs & 29 & & & $*$ & 28 & $104 \%$ & \\
\hline Salaried costs & 74 & & & $*$ & 72 & $103 \%$ & \\
\hline Overheads costs & 371 & & & $*$ & 390 & $95 \%$ & \\
\hline Depreciation & 86 & & & $*$ & 86 & $100 \%$ & $97 \%$ \\
\hline
\end{tabular}

Table 7. OEE-TE September after improvement actions establishment.

\begin{tabular}{|c|c|c|c|c|c|c|c|c|c|c|}
\hline Machines & M1 & M2 & M3 & M4 & M5 & M6 & M7 & M8 & M9 & $\begin{array}{l}\text { TOTAL Plant } \\
\text { September'14 }\end{array}$ \\
\hline $\mathrm{ACP}$ & $95.8 \%$ & $95.8 \%$ & $95.8 \%$ & $95.8 \%$ & $95.8 \%$ & $95.8 \%$ & $95.8 \%$ & $95.8 \%$ & $95.8 \%$ & $95.8 \%$ \\
\hline Availability & $73.0 \%$ & $73.0 \%$ & $73.4 \%$ & $70.7 \%$ & $77.3 \%$ & $75.4 \%$ & $85.6 \%$ & $75.4 \%$ & $70.3 \%$ & $75.0 \%$ \\
\hline $\mathrm{ACP}$ & $97.0 \%$ & $97.0 \%$ & $97.0 \%$ & $97.0 \%$ & $97.0 \%$ & $97.0 \%$ & $97.0 \%$ & $97.0 \%$ & $97.0 \%$ & $97.0 \%$ \\
\hline Performance & $96.2 \%$ & $77.5 \%$ & $92.5 \%$ & $41.2 \%$ & $91.3 \%$ & $40.9 \%$ & $79.1 \%$ & $56.6 \%$ & $46.0 \%$ & $73.2 \%$ \\
\hline $\mathrm{ACP}$ & $97.3 \%$ & $97.3 \%$ & $97.3 \%$ & $97.3 \%$ & $97.3 \%$ & $97.3 \%$ & $97.3 \%$ & $97.3 \%$ & $97.3 \%$ & $97.3 \%$ \\
\hline Quality & $95.4 \%$ & $95.8 \%$ & $94.6 \%$ & $96.4 \%$ & $95.5 \%$ & $83.0 \%$ & $95.2 \%$ & $93.0 \%$ & $88.1 \%$ & $94.5 \%$ \\
\hline OEE-TE September'14 & $67.0 \%$ & $54.2 \%$ & $64.2 \%$ & $28.1 \%$ & $67.4 \%$ & $25.6 \%$ & $64.4 \%$ & $39.7 \%$ & $28.5 \%$ & $51.9 \%$ \\
\hline OEE-TE February'14 & $59.8 \%$ & $47.0 \%$ & $58.3 \%$ & $16.7 \%$ & $59.4 \%$ & $27.5 \%$ & $54.5 \%$ & $27.4 \%$ & $23.2 \%$ & $43.6 \%$ \\
\hline OEE-TE Improvement & $7.2 \%$ & $7.2 \%$ & $5.9 \%$ & $11.4 \%$ & $8.0 \%$ & $-1.9 \%$ & $9.9 \%$ & $12.3 \%$ & $5.3 \%$ & $8.3 \%$ \\
\hline
\end{tabular}

In parallel, questions of: how much is cost saving due to improvement actions in each OEE-contribution factor and how much is one point of the OEE-TE could be answered.

Total savings per month is calculated by using CDR for each contribution factor improvement hour:

Availability: $185 \mathrm{~h} * 200 \mathrm{MAD}=39 \mathrm{KMAD}$

Performance: $329 \mathrm{~h} * 38 \mathrm{MAD}=13 \mathrm{KMAD}$

Quality: $314 \mathrm{~h} * 576 \mathrm{MAD}=181 \mathrm{KMAD}$

Total OEE-TE: 238 KMAD with $1 \mathrm{pt}=29 \mathrm{KMAD}$

As presented in Table 7, the global OEE-TE improvement for each machine and total plant.

Global OEE-TE is improved for all studied machines due to implemented actions except for machine (M6).

\subsection{Return on Experience}

Results:

OEE-TE February: $43.6 \%$

OEE-TE Septembre: $51.9 \%$

Improvement rate: $8.3 \%$

Global Saving cost: 238 KMAD

Cost of one point OEE-TE = 29 KMAD

The proposed approach is very helpful for companies looking for performance improvement of their operational processes. In this case study, OEE-TE was improved by 8.3 points (43.6\% in February VS $51.9 \%$ in September) with a global savings of $238 \mathrm{Kmad}$ per month (One point $=29$ $\mathrm{Kmad})$.

Improvement actions must be maintained and monitored, in parallel a new target is defined to reach higher improvement points and explore total opportunities presented in the case study. So OEE-TE target can be fixed to $85 \%$ for both injection and assembly lines, and opportunities are 33.1 Pts to be reached by an exhaustive use of improvement actions.

\section{Conclusion}

The basic contribution of this paper is to propose a new tool of maintenance performance measurement and improvement based on the combination of Lean and Overall equipment effectiveness approach. Firstly, maintenance activities were mapped and improved via smart improvement actions, then the actual OEE was criticized and improved by taking into consideration technical and economic factors. Proposed factor OEE-TE was associated to lean improvement actions to establish a global effectiveness increasing scheme. It could be easily employed by all maintenance engineers and researchers involved in the problematic of maintenance process.

Process approach is used to describe key activities of maintenance operational processes: preventive and corrective maintenance. Discussed application gives an idea about impact of lean actions on the Overall Equipment Effectiveness, and also the equivalent of quantitative aspect of one point of OEE in term of cost saved.

The proposed tool could be used by researchers and practitioner to have both technical and financial information about maintenance process.

Certainly the proposal can be improved. However the limitation of the proposed model is linking and restricting the study of maintenance process to two main processes, preventive and corrective. 


\section{References}

[1] Ahuja, I. P. S. and Khamba, J. S., (2008) 'Total productive maintenance: literature review and directions', Int. J. Quality and Reliability Management, Vol. 25, No. 7, pp. 709-756.

[2] Atkinson, A. (2007) 'Fixed factor fine tuning', CMA Management, Vol. 81 Issue 7, p42-46.

[3] Badiger, A. S. and Gandhinathan, R. (2008) 'A proposal: evaluation of OEE and impact of six big losses on equipment earning capacity', Int. J. Process Management and Benchmarking, Vol. 2, No. 3, pp. 234-248.

[4] Basirat, P., Fazlollahtabar, H. and Mahdavi, I. (2013) 'System dynamics meta-modelling for reliability considerations in maintenance', Int. J. Process Management and Benchmarking, Vol. 3, No. 2, pp. 136-153.

[5] Bicheno, J. (2000) 'The lean tool box 2nd edition', Piscie books.

[6] DAVIES. C., (2003) 'thesis: The contribution of lean thinking to the maintenance of manufacturing systems', school of industrial and manufacturing science.

[7] Ennhaili, A. Meddaoui, A, Bouami, D. (2014) 'Vers un outil innovant de mesure de performance de la maintenance à l'aide du Value Stream Mapping \& Le Time-Driven Activity Based Costing', Colloque International sur le Monitoring des Systèmes Industriels 25-26 décembre 2014, École Nationale des Sciences Appliquées, Marrakech - Maroc, pp. 2-5.

[8] Elaoufir H., and Bouami D. (2005), 'Les coûts directs de la maintenance: De la comptabilité analytique vers la gestion par les activités', CPI'2005, pp. 1-22. Casablanca, Morocco.

[9] Husby, P and Swartwood. D., (2012) 'Lean: Strengths and Limitations', Encyclopedia of Supply Chain Management. Taylor and Francis, pp. 567-568. New York.

[10] Kaplan, A. and Anderson, S. R. (2006) 'Time-driven activity based costing', Harvard Business Review, pp. 54-68, Boston.

[11] Mabry, B. G. and Morrison, K. R. (1996) 'Transformation to lean manufacturing by an automotive component supplier', Computers and Industrial Engineering, Vol. 31, Nos. 1-2, pp. 95-98.

[12] Mathaisel, D. F. X. (2005) 'A lean architecture for transforming the aerospace maintenance, repair and overhaul (MRO) enterprise', International Journal of Productivity and Performance Management, Vol. 54, No. 8, pp. 623-644.
[13] Meddaoui, A. and Bouami, D. (2013) 'Cost modelling in maintenance using time-driven activity-based costing', Int. J. Productivity and Quality Management, Vol. 12, No. 3, pp. 247-270.

[14] Meddaoui, A. and Bouami, D. (2014) 'Decision making in maintenance using analytical hierarchy process and time driven activity based costing', Int. J. Productivity and Quality Management, Vol. 13, No. 4 pp. 450-470.

[15] Nakajima, S. (1988) 'introduction to TPM total productive maintenance', productivity press.

[16] Ohno, T. (1985)'Kanban: Just in time at Toyota', productivity press.

[17] Saleem, M., Khan, N., Hameed, S. M. and Abbas, M. (2012) 'An analysis of relationship between total quality management and Kaizen', Life Science Journal, Vol. 9, No. 3, pp. 31-40.

[18] Sawhney, R. and Subburaman. K., (2009) 'A modified FMEA approach to enhance reliability of lean systems'Int. J. Quality \& Reliability Management, Vol. 27, No. 7, pp. 832-855.

[19] Salonen, A. and Deleryd, M. (2011) 'Cost of poor maintenance - a concept for maintenance performance improvement', Journal of Quality in Maintenance Engineering, Vol. 17, No. 1, pp. 63-73.

[20] Sawhney, R. Kannan, S. and Xueping Li, (2009) 'Developing a value stream map to evaluate breakdown maintenance operations'Int. J. Industrial and Systems Engineering, Vol. 4, No. 3, pp. 229-240.

[21] Singh, J. and Singh, H. (2014) 'Performance enhancement of a manufacturing industry by using continuous improvement strategies - a case study', Int. J. Productivity and Quality Management, Vol. 14, No. 1, pp. 36-65.

[22] Womack, J. P., Jones, D. T. and Roos, D. (1990) 'The Machine That Changed The World'; The Story of Lean Production, Rawson Associates, New York.

[23] Wu, S. and Wee, H. M. (2009) 'How lean supply chain effects product cost and quality - a case study of the Ford Motor Company', 6th International Conference on Service Systems and Service management, 8-10 June, Xiamen University, Fac Management, Xiamen, IEEE, Vols. 1 and 2, pp. 271-276.

[24] Womack, P. J. and Daniel, T. J. (1996) Lean Thinking: Banish Waste and Create Wealth in Your Corporation, pp. 29-90, Simon \& Schuster, UK. 